\title{
Literature Review on Relationship Building for Community-academic Collaboration in Health Research and Innovation
}

\author{
Choiwai Maggie Chak ${ }^{1}$ \\ ${ }^{1}$ Science-to-Business Marketing Research Centre, FH Münster
}

\begin{abstract}
In response to European Commission Horizon 2020's call for 'science-for-and-withcommunity', scholars have recognized the need to conduct 'responsible research and innovation' and engage more with communities to combat today's complex health challenges. Hence, higher priority has been placed to cooperate with communities in health research and innovation development to better match societal values, needs and expectations. Accordingly, the approach of community-based participatory research (CBPR), the 'gold standard' within the communityengaged research spectrum, is the most widely discussed. However, it is seldom achieved in reality, as it requires establishment and maintenance of open, transparent, trustful and ongoing relationships between community partners and academia to succeed. Paradoxically, despite of the significance of quality collaborative relationship to the quality and success of communityacademic collaboration, the key elements to achieve it were seldom discussed.Herein, the literature review aimed to (1) discuss the previous experiences and challenges in building and sustaining community-academic collaborative relationships; (2) examine the relationship building strategies for quality collaborative relationships; and (3) identify the potential research gaps for future research.Focusing on the area of health research and innovation, peer-reviewed articles, books and grey literature related to building and sustaining relationships in communityacademic collaboration published between 1998 and 2018 were identified using the Web of Science, PubMed and Google Scholar bibliographic databases and Google search engine. Literature available in full-texts and English language with a focus on relationship aspects of community-academic collaboration were examined. Previous literature suggested thatacademics and community members encountered common challenges in experiencing inequitable relationships, distrust, divide between academia and community, uncommon norms of power sharing, dissemination of results and lack of resources for maintaining long-term relationships. Two approaches of relationship building: (1) personal qualities and competence, and (2) actions for relationship building from the beginning to the end stages of collaborative relationship were discussed. Literature revealed that the ways that academics approach, collaborate, communicate with and maintain in the community had significant impact on both current and future collaborative relationships. In addition, academics differed in acceptance and readiness towards community engagement, which could be attributed to the differences in personal qualities and competence. Future research should target on identifying the factors contributing to such individual differences and compare its impact on the quality of relationship with community, so as to better cultivate individuals' readiness and capacity towards community engagement and effective relationship building with community. KEYWORDS: LITERATURE REVIEW, RELATIONSHIP BUILDING, RESPONSIBLE RESEARCH AND INNOVATION, COMMUNITY-ACADEMIC COLLABORATION, HEALTH
\end{abstract}

\section{Introduction}

\subsection{Research Background}

In response to European Commission Horizon 2020's call for 'science-for-and-with-community', academia have recognized the need to conduct 'responsible research and innovation' via engaging with communities to combat today's complex health challenges(Jacob, 2013). Hence, universities have given higher priority to community engagement in the aim of better aligning health research and innovation development to meet the societal values, needs and expectations (Trencher et al., 2017; van Hove and Wickson, 2017).

Accordingly, community-engaged research, a collaborative approach which addresses health inequities via engaging community stakeholders as partners in health research process (Ross et al., 2010; Wang et al., 2017), has been increasingly valued in health research and innovation (Israel et al., 2006; 
Provan, Harvey and Zapien, 2005). Community-based participatory research (CBPR), which is the 'gold standard' among the whole community-engaged research spectrum, is the most widely discussed approach over the last two decades (LaVeaux and Christopher, 2009; Winterbauer et al., 2016). It emphasises equal partnerships with equitable involvement, equal authority and responsibility between academia and community partners at all stages of research process (Israel et al., 1998; Israel, 2005; Katz, 2003; Minkler, 2005; Ross et al., 2010), which addresses power imbalances across the whole spectrum of community engagement (Wallerstein et al., 2005).

\subsection{Knowledge gap}

Despite the emerging discussions on its importance and availability of case studies, an immaculate CBPR is seldom achieved in reality (Blumenthal 2011), as it demands (1) mutual understanding and respectful trust between community partners and academia; (2) commitment to partnership development and sustainability; (3) acknowledgement and reduction of power imbalances and tension in relationships and (4) operationalization of equity among partners(Winterbauer and Myers, 2013), all of which must be built upon quality, cooperative and sustainable relationships between community partners and academics (Mayan and Daum, 2016; Wang et al., 2017).

Hence, establishing and sustaining open, transparent, trustful and ongoing relationships between community partners and academia is highly essential for CBPR(Ahmed et al., 2016; Israel et al., 1998; Lemacks, Landry and Wenzler, 2018; Rothman and Gass, 2000). It helps partners to understand each other's concerns, interests, and needs and incorporating them into the development agenda (Minkler et al., 2017), to implement strategies responsive to the needs, priorities, and values of the community (Huang, Lipman and Daniel Mullins, 2017) and to obtain synergy from all partners (CDC, 2011; Lasker, Weiss and Miller, 2001). It is also a key driver to university-community collaboration quality and success (Ahmed et al., 2016; Bahraminejad et al., 2015; Christopher et al., 2008; Serrell et al., 2009).

However, despite quality collaborative relationships are fundamental for the success of community-academiccollaboration, there are limited discussions on how to achieve them in literature (Mayan and Daum, 2016; Netshandama, 2010), such as ways to strengthen understanding of stakeholders' relationship objectives, responsiveness of coordination, access and service to community needs, and to ensure relationship sustainability (Netshandama, 2010).

Hence, the questions are: how well did academia and community stakeholders establish and maintain collaborative relationships in community-academic collaboration? What challenges did they face in such relationships? What approaches could be adopted to strengthen the bridging and alignment of goals between the stakeholders? Answering these questions will provide us the insights to facilitate quality collaborative relationships essential for better collaborative outcomes for health research and innovation.

\subsection{Aims of research}

In response to the questions, the aims of this literature review are to: (1) discuss the previous experiences and challenges in building and sustaining community-academic collaborative relationships; (2) examine the relationship building strategies for quality collaborative relationships; and (3) identify the potential research gaps that should be discussed in future research.

\section{Methods}

The search of literature was performed with the use of the Web of Science, PubMed and Google Scholar bibliographic databases and Google search engine to identify peer-reviewed articles, books and grey literature including organisational reports, case reports over the last two decades (between 1998 and 2018). The scope of literature review covered topics regarding to relationship aspects for health research and innovation in community-academic collaboration contexts, including responsible research and innovation (RRI), community-academic partnership (CAP), universitycommunity collaboration (USC), community-based participatory research (CBPR), and community-engaged research (CEnR).

Articles included in the review were the literature that mainly focused on describing the relationships between universities or academics with community stakeholders in partnerships or collaboration for community-engaged health projects. Only full-texts studies in English languages were included and examined in the review. Nevertheless, they were not limited to geographical locations, so as to gain a better picture of the global situation.

\section{Results}

\subsection{Challenges in establishing and sustaining collaborative relationships between academics and community}

Despite the goodwill of engaging the community in research and innovation development, a number of literature suggested that establishing and sustaining quality collaborative relationships between academia and community depicted by CBPR could be easier said than done (Blumenthal, 2011; Council of Higher Education, 2004; Eden, Jirotka and Stahl, 2013). The followings are the prominent challenges reported from both sides: 


\subsubsection{Inequitable relationship}

Achieving a collaborative and equitable relationship is one of the biggest challenges in realising CBPR. This is attributed to academics' common perception of community engagement as an 'add-on, nice-to-have and philanthropic act'(Council of Higher Education, 2004). The educational expertise provided academics the scientific privilege, legitimacy and power in research (Cherry and Shefner, 2004; Davies et al., 2009). Consequently, academia often assumed that its knowledge exceeded the community's understanding of its own needs, subsequently reassured their expertise in identifying the community's 'problems', providing 'solutions' by treating the community as inferior ones (Katz, 2003; Tippins, Bell and Lerner, 1998). One example was the labelling of the communities that participated in the community-engaged programs and research as 'low-income', 'at risk' or 'marginalised'(CDC, 2011; Fletcher et al., 2013). As a result, academics tended to play a dominating and paternalistic position in collaborative relationships (Provan, Harvey and Zapien, 2005), prioritizing their interests over those of the community (Netshandama, 2010), and controlling the research process ranging from resources, methods, to dissemination of results (Winterbauer et al., 2016; Winterbauer and Myers, 2013). Such power imbalance in community-academic relationships was not uncommon and often lead to distrust, disrespect and impeded willingness to collaborate in community, and subsequently, tensions and conflicts in projects (Dempsey, 2010; Netshandama, 2010).

\subsubsection{Uncommon norms ofpower sharing}

Power sharing advocated in community engagementis a significantly different norm compared to conventional research. Adopting community engagementimplies thatacademicsmustlet down some or evenly distribute their power to community stakeholders(Rothman and Gass, 2000).Therefore, community engagement could be seen as beneficial to researchers but also a dilution of return in contribution and investment (Grand et al., 2015).Certain academics found their standard modes of operation and primary professional obligation of producing publishable resultsmore comfortable and achievable than venturing into community engagement with more dispersed goals(Dempsey, 2010; Miller et al., 2015). Recent research also supported that some scholars were still cautious or reluctant towards community engagement, suggesting the conventional notions and norms of science were still vivid (Petrescu, 2017; van Hove and Wickson, 2017).

Even when academics desired to engage community or recognised the necessity of power shift to genuinely collaborate with community in projects, many of them found it difficult to or were uncomfortable about releasing the control, working and sharing credits, responsibility and ownership of research with the community (Staley, 2009),particularly because academics' professional identities as experts have been long built upon years of knowledge, skills and craft development, which was highly important among academia (Staley, 2009), as their professional value depended on theexclusive possession of expertise (Ahmed et al., 2004)and control of ideas, data and intellectual property(Grand et al., 2015).

Likewise, the conventional perceptionofbeing the passive recipients of knowledge and technology transfer still had significant influences on the community side, which madecommunity stakeholders uncomfortable in expressing their needs and priorities to academic partners in a collaboration(Allen et al., 2011).

\subsubsection{Distrust between partners}

Even when scholars incorporated community into their research, it was often that they did not truly work 'with' the community partners as defined by CBPR approach, rather conducted a community-based research 'in' the community where community members were served as passive participants (GarcíaRivera et al., 2017; Horowitz, Mimsie Robinson and Seifer, 2009). This resulted in debatable extent of genuine reciprocity and dialogue in community engagement (Horst and Michael, 2011) that could be detrimental to the relationship between partners. One indicator was that there was a general distrust among academia to involve the public in any processes of decision-making, despite they agreed on the contribution to public good as the purpose of research funding allocation (Eden, Jirotka and Stahl, 2013).

Equally, Netshandama (2010) reported coherent distrust from community stakeholders' view towards university-community partnerships. Community members found scholars untrustworthy, as they seldom devote time to maintain the collaborative relationships or show commitments to improve the communities' well-being(Netshandama, 2010). Instead, theyused 'community engagement' to address their own needs andto justify their political correctness in spite of undermining community's voice in actual discussions (Netshandama, 2010). Consequently, most community members and leaders could not see any value in establishing collaborative relationships with academics who did not put the community's interests in mind and were non-differential to community needs (Ahmed et $a l .$, 2004; Gass, 2005). When conventional paternalistic, manipulative and exploitativeresearch approach was applied to community engagement, it could erode community's trust to partner with academics (Netshandama, 2010).

\subsubsection{Divides between academia and community}

Ideally, academia should integrate themselves withthe communityincollaborative partnerships. Paradoxically, academia often perceived themselves to be divided from their wider community (Dempsey, 
2010; Minkler, 2004). Hence, academics who participated in community engagement often got into the community looking for research support but quitted its relationship withthe community once the research was completed without any gratitude or even left without ensuring the project could be successfully continued in community(Netshandama, 2010). Such boundary-dividing approach made communities feel disempowered and dependent. It also further distanced the communities from academia (Netshandama, 2010).As a result, community underwent these unfavourable experiences often held the perception of being manipulated by academia rather than being involved (Davis, Cook and Cohen, 2005; Katz, 2003; Netshandama, 2010), which often resulted in distrust in relationships and avoidance of future collaboration with academics who considered themselves as the 'outsiders' of a community.

\subsubsection{Knowledge Dissemination}

It is reported that academics sometimes offered the community no information about the results nor direct benefits for their participation(Ahmed et al., 2016; Davis, Cook and Cohen, 2005; Grand et al., 2015; Huang, Lipman and Daniel Mullins, 2017; Netshandama, 2010).On the other hand, when academics collaborated with industry for the commercialization of health innovations and products, itgave rise to the concern of conflicts of interest (Miller et al., 2015), as academic patenting could indirectly cause constraints on the free flow of information with community members (Miller et al., 2015), such thatacademics were unwilling to disclose all information about their community projects. Withholding information also damage the reciprocity and trust in the relationship between community and academics.

\subsubsection{Lack of resources for maintaining long- term relationships}

Academics often experienced significant challenges in securing long-term funding and resources. Not only did the funding typically vulnerable to political changes (Miller, 2001), compared to traditional research initiatives, research with community engagement often required increased time, resource burdens and extra efforts in planning identification of additional resources and relationship building, which lead to lower access and competitiveness in grant applications (García-Rivera et al., 2017). As a result, previous research literature not only reported lack of access to community, but also lack of funding, time, and opportunities and resources to effectively engage community and sustain relationships(Lemacks, Landry and Wenzler, 2018). For example, research targeting hard-to-reach communities required more time for relationship development (Lemacks, Landry and Wenzler, 2018). Limited resources for relationship building could reduce relationship building activities.
Otherwise, academics must support at their personal expenses(Lemacks, Landry and Wenzler, 2018).

\subsection{Relationship building approaches}

Existing literature, however, suggested that community-academic relationships could be built and sustained in two ways: (1) personal qualities such as skills, attributes, virtues of academics on nurturing relationships with community members(Mayan and Daum, 2016; Pinto, 2009; Pinto, McKay and Escobar, 2008) and competence (Shineha et al., 2017), as well as (2) actions targeted on relationship building (Huppert, 2000; Mayan and Daum, 2016).

\subsubsection{Personal qualities and competence}

Literature reporting successful casesalso highlighted the essential social skills and attributes of academics such as friendliness, honesty, caring, empathy, compassion, concern, and commitment and openness (Pinto, McKay and Escobar, 2008; Pinto, 2009) in facilitating relationship building for partnerships. For instance, certain academics succeeded in maintaining good relationships with community partners as they were great listeners, open-minded, culturally competentand respectful to all partners (Christopher et al., 2008), whom were later framed as the 'boundary spanners'(Weerts and Sandmann, 2010). It refers to individuals who often engage themselves in sustaining effective personal relationships with other circles and arehighly motivated to collaborate with different stakeholders for mutually beneficial outcomes(Weerts and Sandmann, 2010).

Apart from personal qualities, academics' competence for interdisciplinary or intersectoral collaboration could also be cultivated via provision of rapid and intense crash courses, workshops and trainings on community engagement and relationship building with community members, such as the basic languages and approaches used in other fields and sectors (van Hove and Wickson, 2017). This could support and promote academics'cultural competence and readiness for establishing effective communityacademic collaboration relationships(Andrews et al., 2012; Shineha et al., 2017).

\subsubsection{Actions targeting on relationship building}

Previous literature suggested a number of actionsthat facilitate relationship building at different stages of collaboration to enhance equity, transparency and eliminate power imbalance and hierarchy in relationships, which could be categorised into (1) actively approaching the community before collaboration, (2) early stage of establishingtrustful, collaborativerelationships, (3) facilitating smoother relationships during collaboration, and (4) sustaining relationships after collaboration. 


\subsubsection{Actively approaching community before collaboration}

In order to effectively engage the community, academics must first gain entry to the community and build trust with the community stakeholders before establishing collaborative relationships (Caine, Davison and Stewart, 2009; Mayan and Daum, 2016; Pinto, McKay and Escobar, 2008). One way of connecting to and becoming the 'insider' of the community is by paying visits to the community (Huppert, 2000; Pinto, McKay and Escobar, 2008)and participating in community tours led by community leaders before approaching the community for collaboration. The aim isto first understand, respect and valuetheir operational norms and cultures (Huppert, 2000). These acts not onlyencourageinformal conversations andfoster academics' interests and understanding to community issues, but also show goodwill to the potential community partners and increase the chance of success and effectiveness of establishinga new collaborative relationship with a proposal that meet their needs(Mayan and Daum, 2016). In addition, establishing informal relationships (such as participating in community events or informal lunch meetings) and casual conversations with community could also help academics reduce hierarchy and get into the community more easily (Christopher et al., 2008).

\subsubsection{Early stage of establishingcollaborative relationships}

To establish a trusting and quality collaborative relationship, honesty, reciprocity and transparency between partners are essential. Upon the start of collaborative relationships, all partners should(1) make their needs and goals explicit and establish a common ground(Stilgoe, Owen and Macnaghten, 2013); (2) be committed to the project goals(Huang, Lipman and Daniel Mullins, 2017); (3) establish a communication plan to remain well-informed in the research process(Andrews et al., 2012;Roberts et al., 2013; Huang, Lipman and Daniel Mullins, 2017); (4) maintain the flexibility to negotiateand revise changes in the project's goals or strategies (Huang, Lipman and Daniel Mullins, 2017); and(5) be willing to work through disagreement and maintain mutual respect when consensus are not reached(Katz, 2003).

To achieve this, having an open dialogue with community partners is a prerequisite (Minkler, 2004). All partners should (1) explain the reasons for interest in establishing a relationship and the timeline in clarity and honesty, (2) negotiate each other's formal roles and expectations (Huppert, 2000; Winterbauer et al., 2016); and (3) be committed to disclose and share information and results to community members (García-Rivera et al., 2017).

Both parties should understand the fact that there may not be adequate resources and capacity to address all needs. Thus, the interests, priorities, possibilities and limitations between partners should be openly and clearly discussed at early stage of partnerships, since community stakeholders highly valued the openness(García-Rivera et al., 2017).

In terms of formal roles and expectations, each member should indicate their ways of participation and expected levels of effort. One way to eliminate power imbalance and hierarchies in partnership is to ensure a proportional representation in meetings (e.g. balanced number of community stakeholders and academics) and a rotation of leadership and task assignment (e.g. designating different leaders at each study phase)between academia and community stakeholders to ensure that a diversity and equity of voices (Provan, Harvey and Zapien, 2005).To assure all members understand their formal roles and responsibilities in partnerships, tools such as Memoranda of Agreement, contracts stating the scope and standard of work, or signed letters of understanding could promote the formalization of discussions and agreements (Huppert, 2000).

Despite the potential presence of conflicts of interests where academics may not be able to disclose all information to the community members, academics should address the issue at the beginning of collaboration and negotiate with members on which information to share and be committed to disclose them to community members(Banks et al., 2013).

Afterwards, a comprehensive needs assessment should be conducted to identify partners' needs and priorities of the communities served (Gwede et al., 2010; Luque et al., 2011; Simmons et al., 2015), and acknowledge and accommodate different timelines, goals and be flexible in negotiating the priorities with community.

Meanwhile, offering seed funding for projects was proved to be essential for community stakeholdersto support their time and foster commitment to the project(Allen et al., 2011; Luque et al., 2011; Shineha et al., 2017), hence it could be beneficial to the early relationship building stage.

\subsubsection{Facilitating smoother relationships during collaboration}

During collaboration or partnership, the communication frequency and quality between partners should be regular, otherwise infrequent communication would give the community members an impression that one only gets in touch when something is needed from them (Huppert, 2000). Regular dialogue via meetings, phone calls, e-mails provide updates on the progress of project could ensure academics get updated information from the community, keeps partners engaged and offer renewal of relationships(Huppert, 2000; Luque et al., 2011).

In terms of communication language, academicsshould avoid theoretical, impersonal terms and jargons, as they are found to be intimidating to community stakeholders (Huang, Lipman and Daniel Mullins, 2017). Hence, communication channels 
including local presentations, group discussions, and newsletters should be in common and culturally appropriate language and storytelling approach (GarcíaRivera et al., 2017; Luque et al., 2011). Meetings organised within the community and active listening could allow community stakeholders to be physically and psychologically stay in the community (Cherry and Shefner, 2004) and be more comfortable to express their views (Trench, 2008).

It is alsohighly important to recognise and reward the efforts of both community and academic stakeholders, as in many situationsthe participation of members in partnerships were voluntary or underpaid. For example, community members who helped generate the intellectual property rights or knowledge (Netshandama, 2010)should beincluded as co-authors or in acknowledgement of abstracts, posters or manuscripts to maintain trust and respect in collaborative relationships (García-Rivera et al., 2017).

Another approach is to recognise partners'leadership and contribution with an award or a featurestory in the local media to honourtheir accomplishments(del Pino et al., 2016). Partners could take action to write a nomination letter for a community award, or introduce one's great work to the media to promote the experiences of community collaboration and honourtheir roles as local agents of change in health and well-being of community(del Pino et al., 2016; García-Rivera et al., 2017).

If possible, compensating academics or community partners with certificate or coupons to a restaurant or bookstore as a gesture of contribution recognition is also be appreciated(Huppert, 2000). Otherwise, positive reinforcement measures such as giving a letter of congratulation or praise from the dean could also help maintain good relationships via demonstratinggratitude to partners' contribution and effort (Huppert, 2000).

\subsubsection{Sustaining relationshipsafter collaboration}

Quality partnerships requires long-term relationship building among stakeholders to maintain commitment and interests during and after the collaboration period.To ensure sustainability, academics should slowly pace out by empowering community to monitor the results and offer assistance at the end of the project instead of leaving the community alone immediately. To avoid the impression of manipulation and exploitation, academics should stay engaged in the community via continue getting involved in community life(Staley, 2009). Such practices could be supported on organisational level. For instance, instead of evaluating academics purely based on their academic publications, higher education policymakers could also include public outreach work (such as engagement and dissemination work in addition to teaching and research) as the evaluation criteria for employment and promotion in scientific positions (Shineha et al., 2017) to provide motivation for academics to sustain their relationships with community.

\section{Conclusions and recommendations}

Nowadays, academics are undeniably more expected to step out of their 'ivory tower', extend their boundaries to bridge with their wider community in order to achieve better and more accepted research and innovation outcomes.Accordingly, the purpose of this literature review is to offer academics and community stakeholders insights on the common situations, challenges and pitfalls in building and maintaining community-academic collaborative relationships and to demonstrate ways to build stronger collaborative relationships.

From literature it is clear that the ways how academics approach, collaborate, communicate with and stay in the community demonstrated significant impact ontheir relationships, which could eventually influence not only the quality, processes, impact and sustainability of the existing collaborations or partnerships, but also the potentials of future collaborations. Hence it is extremely crucial for academics to acknowledge and be well-prepared of the pitfalls and be capable to deal with the potential tensions and conflicts that may arise before initiating collaborative relationships with community members. CBPR has offered a valuable insight to achieve that via establishing an equitable, transparent, trustful relationship with community. Although there is still plenty of room for improvement in practice, a huge progress has been made over the last two decades.

Morevoer, it is worth notice that literature has offered valuable insights to the effect of individual differences towards relationship building for community engagement. Apparently, some academics were more open-minded while some were still reluctant to accept or had concerns about community engagement, or some started community engagement activities despite of the lack of enough knowledge about its true essence. Accordingly, they faced various types of challenges, ranging from starting a new collaborative relationship to sustaining an existing relationship. Therefore, future research may consider to explore the differences of acceptance and readinessamong academics towards community engagement andidentify the factors contributing to such differences. Given personal qualities and competence could be a unique approach for relationship building, comparing how academics' individual qualities and competence may affect the quality of relationship with communitycould also benefit thecultivation of their readiness and capacity in promoting community engagement andeffective relationship building with community.

\section{$5 \quad$ Reference list}

[1] Ahmed, S.M. et al. (2004) 'Overcoming Barriers to Effective Community-Based Participatory 
Research in US Medical Schools', Education for Health (Abingdon, England), 17(2), 141-151. doi: $10.1080 / 13576280410001710969$

[2] Ahmed, S.M. et al. (2016) 'Opening the Black Box: Conceptualizing Community Engagement from 109 Community-Academic Partnership Programs', Progress in Community Health Partnerships : Research, Education, and Action, 10(1), 51-61. doi: 10.1353/cpr.2016.0019

[3] Allen, M.L. et al. (2011) 'A Capacity Building Program to Promote CBPR Partnerships between Academic Researchers and Community Members', Clinical and Translational Science, 4(6), 428-433. doi: 10.1111/j.1752-8062.2011.00362.x

[4] Andrews, J.O. et al. (2012) 'Partnership Readiness for Community-based Participatory Research', Health Education Research, 27(4), 555-571. doi: 10.1093/her/cyq050

[5] Bahraminejad, N. et al. (2015) 'Partner's Engagement in Community-based Health Promotion Programs: a Case Study of Professional Partner's Experiences and Perspectives in Iran', Health Promotion International, 30(4), 963-975. doi: 10.1093/heapro/dau043

[6] Banks, S. et al. (2013) 'Everyday Ethics in Community-based Participatory Research', Contemporary Social Science, 8(3), 263-277. doi: 10.1080/21582041.2013.769618

[7] Blumenthal, D.S. (2011) 'Is Community-Based Participatory Research Possible?' American Journal of Preventive Medicine, 40(3), 386-389. doi: 10.1016/j.amepre.2010.11.011

[8] Caine, K.J., Davison, C.M. and Stewart, E.J. (2009) 'Preliminary Field-work: Methodological Reflections from Northern Canadian Research', Qualitative Research, 9(4), 489-513. doi: $10.1177 / 1468794109337880$

[9] Center for Disease Control and Prevention (ed.) (2011) Principles of Community Engagement. 2nd edn. USA: National Institutes of Health.

[10] Cherry, D.J. and Shefner, J. (2004) 'Addressing Barriers to University-Community Collaboration', Journal of Community Practice, 12(3-4), 219-233. doi: 10.1300/J125v12n03_13

[11] Christopher, S. et al. (2008) 'Building and Maintaining Trust in a Community-based Participatory Research Partnership', American Journal of Public Health, 98(8), 1398-1406. doi: 10.2105/AJPH.2007.125757

[12] Council of Higher Education (2004) Chapter Seven: Community Engagment. [online] available from https://innerweb.ukzn.ac.za/scer/ Council\%20on\%20Higher\%20Education/SA_HE_ 10years_Nov2004_Chapter7.pdf [09 June 2018].

[13] Davies, S.R. et al. (2009) 'Discussing Dialogue: Perspectives on the Value of Science Dialogue Events that Do Not Inform Policy', Public Understanding of Science, 18(3), 338-353.

[14] Davis, R., Cook, D. and Cohen, L. (2005) 'A Community Resilience Approach to Reducing
Ethnic and Racial Disparities in Health', American Journal of Public Health, 95(12), 2168-2173. doi: 10.2105/AJPH.2004.050146

[15] del Pino, H.E. et al. (2016) 'Integrating Community Expertise into the Academy: South Los Angeles' Community-Academic Model for Partnered Research', Progress in Community Health Partnerships: Research, Education, and Action, 10(2), 329-338. doi: $10.1353 /$ cpr.2016.0028

[16] Dempsey, S.E. (2010) 'Critiquing Community Engagement', Management Communication Quarterly, doi: $10.1177 / 0893318909352247$ 24(3), 359-390.

[17] Eden, G., Jirotka, M. and Stahl, B. (2013) Responsible Research and Innovation: Critical Reflection Into the Potential Social Consequences of ICT.Proceedings of the IEEE 7th International Conference on Research Challenges in Information Science (RCIS). Held May 29-31, 2013 at Paris, France : $1-12$.

[18] Fletcher, F. et al. (2013) 'Needs and Readiness Assessments: Tools for Promoting Communityuniversity Engagement With Aboriginal Communities', Gateways: International Journal of Community Research and Engagement, 6(1), 131. doi: 10.5130/ijcre.v6i1.3219

[19] García-Rivera, E.J. et al. (2017) 'Building Bridges to Address Health Disparities in Puerto Rico: the "Salud para Piñones" Project', Puerto Rico Health Sciences Journal, 36(2), 92-100.

[20] Gass, E. (2005) 'The Path to Partnership: A New Model for Understanding University-Community Partnerships', Professional DevelopmentPhiladelphia, 8, 12-23.

[21] Grand, A. et al. (2015) 'Mapping Public Engagement With Research in a UK University', PloS One, 10(4), e0121874. doi: 10.1371 /journal.pone. 0121874

[22] Gwede, C.K. et al. (2010) 'Strategies for Assessing Community Challenges and Strengths for Cancer Disparities Participatory Research and Outreach', Health Promotion Practice, 11(6), 876-887. doi: $10.1177 / 1524839909335803$

[23] Horowitz, C.R., Mimsie Robinson, R. and Seifer, S. (2009) 'Community-Based Participatory Research from the Margin to the Mainstream: Are Researchers Prepared?' Circulation, 119(19), 2633-2642. doi: 10.1161/CIRCULATIONAHA.107.729863

[24] Horst, M. and Michael, M. (2011) 'On the Shoulders of Idiots: Re-thinking Science Communication as 'Event", Science as Culture, 20(3), 283-306. doi: $10.1080 / 09505431.2010 .524199$

[25] Huang, J., Lipman, P.D. and Daniel Mullins, C. (2017) 'Bridging the Divide: Building Infrastructure to Support Community-academic Partnerships and Improve Capacity to Conduct Patient-centered Outcomes Research', 
Translational Behavioral Medicine, 7(4), 773-782. doi: 10.1007/s13142-017-0487-z

[26] Huppert, M.E. (2000) 'Principle 6: Roles, Norms, and Processes for the Partnership Are Established with Input and Agreement of All Partners', Partnership Perspectives, 1(2), 47-55.

[27] Israel, B.A. (2005) Methods in Community-based Participatory Research for Health. San Francisco, CA: Jossey-Bass [online] available from http:// site.ebrary.com/lib/alltitles/docDetail.action? docID=10304499 [09 June 2018].

[28] Israel, B.A. et al. (1998) 'Review of Communitybased Research: Assessing Partnership Approaches to Improve Public Health', Annual Review of Public Health, 19, 173-202. doi: 10.1146/annurev.publhealth.19.1.173

[29] Israel, B.A. et al. (2006) 'Challenges and Facilitating Factors in Sustaining CommunityBased Participatory Research Partnerships: Lessons Learned from the Detroit, New York City and Seattle Urban Research Centers', Journal of Urban Health : Bulletin of the New York Academy of Medicine, 83(6), 1022-1040. doi: 10.1007/s11524-006-9110-1

[30] Jacob, K. (2013) Options for Strengthening Responsible Research and Innovation: Report of the Expert Group on the State of Art in Europe on Responsible Research and Innovation. Luxembourg: Publications Office of the European Union.

[31] Katz, D.L. (2003) 'Representing Your Community in Community-based Participatory Research: Differences Made and Measured', Preventing Chronic Disease, 1(1).

[32] Lasker, R.D., Weiss, E.S. and Miller, R. (2001) 'Partnership Synergy: A Practical Framework for Studying and Strengthening the Collaborative Advantage', The Milbank Quarterly, 79(2), 179205. doi: 10.1111/1468-0009.00203

[33] LaVeaux, D. and Christopher, S. (2009) 'Contextualizing CBPR: Key Principles of CBPR meet the Indigenous research context', Pimatisiwin, 7(1), p. 1.

[34] Lemacks, J., Landry, A. and Wenzler, P. (2018) 'Formative research to identify community partnerships and foster relationships for health promotion research in South Mississippi', Public Health. doi: 10.1016/j.puhe.2018.01.023

[35] Luque, J.S. et al. (2011) 'A Social Network Analysis Approach to Understand Changes in a Cancer Disparities Community Partnership Network', Annals of Anthropological Practice, 35(2). doi: 10.1111/j.2153-9588.2011.01085.x

[36] Mayan, M.J. and Daum, C.H. (2016) 'Worth the Risk? Muddled Relationships in CommunityBased Participatory Research', Qualitative Health Research, 26(1), 69-76. doi: $10.1177 / 1049732315618660$

[37] Miller, F.A. et al. (2015) 'Citizen Expectations of 'Academic Entrepreneurship' in Health Research:
Public Science, Practical Benefit', Health Expectations : an International Journal of Public Participation in Health Care and Health Policy, 18(6), 2356-2374. doi: 10.1111/hex.12205

[38] Miller, S. (2001) 'Public Understanding of Science at the Crossroads', Public Understanding of Science, 10, 115-120.

[39] Minkler, M. (2004) 'Ethical Challenges for the "Outside" Researcher in Community-Based Participatory Research', Health education \& behavior : the official publication of the Society for Public Health Education, 31(6), 684-697. doi: $10.1177 / 1090198104269566$

[40] Minkler, M. (2005) 'Community-based Research Partnerships: Challenges and Opportunities', Journal of Urban Health : Bulletin of the New York Academy of Medicine, 82(Suppl 2), ii3-ii12. doi: $10.1093 /$ jurban/jti034

[41] Minkler, M. et al. (2017) Community-based Participatory Research for Health : Advancing Social and Health Equity [online] available from http://www.myilibrary.com/?id=1041315 [09 June 2018].

[42] Netshandama, V. (2010) 'Quality Partnerships: the Community Stakeholders' View', International Journal of Community Research and Engagement, 3(0), 70. doi: 10.5130/ijcre.v3i0.1541

[43] Petrescu, A.M.A. (2017) 'Ways of Valorizing The Public Engagement In Responsible Research And Innovation', 2nd Central and Eastern European LUMEN International Conference Multidimensional Education and Professional Development. Ethical Values, 2016: Cognitivecrcs, 617-622. doi: 10.15405/epsbs.2017.07.03.72

[44] Pinto, R.M. (2009) 'Community Perspectives on Factors That Influence Collaboration in Public Health Research', Health Education \& Behavior : The Official Publication of the Society for Public Health Education, 36(5), 930-947. doi: $10.1177 / 1090198108328328$

[45] Pinto, R.M., McKay, M.M. and Escobar, C. (2008) "'You've Gotta Know the Community": Minority Women Make Recommendations About Community-Focused Health Research', Women \& Health, $\quad 47(1), 83-104$. doi: 10.1300/J013v47n01_05

[46] Provan, K.G., Harvey, J. and Zapien, J.G. de (2005) 'Network Structure and Attitudes Toward Collaboration in a Community Partnership for Diabetes Control on the Us-mexican Border', Journal of Health Organization and Management, 19(6), 504-518. doi: 10.1108/14777260510629706

[47] Roberts, C.B. et al. (2013) 'Lessons Learned From Building an Infrastructure for Community-engaged Research', International Public Health Journal, 5(1), 7-16.

[48] Ross, L.F. et al. (2010) 'The Challenges of Collaboration for Academic and Community Partners in a Research Partnership: Points to Consider', Journal of Empirical Research on 
Human Research Ethics : JERHRE, 5(1), 19-31. doi: 10.1525/jer.2010.5.1.19

[49] Rothman, N.L. and Gass, D.L. (2000) 'A Successful Community-based Partnership: Formation and Achievements.', Metropolitan Universities, 11(2), 59-62.

[50] Serrell, N. et al. (2009) 'An Academic-community Outreach Partnership: Building Relationships and Capacity to Address Childhood Lead Poisoning', Progress in Community Health Partnerships : Research, Education, and Action, 3(1), 53-59. doi: $10.1353 /$ cpr.0.0056

[51] Shineha, R. et al. (2017) 'Science Communication in Regenerative Medicine: Implications for the Role of Academic Society and Science Policy', Regenerative Therapy, 7, 89-97. doi: 10.1016/j.reth.2017.11.001

[52] Simmons, V.N. et al. (2015) 'Participatory Evaluation of a Community-academic Partnership to Inform Capacity-building and Sustainability', Evaluation and Program Planning, 52, 19-26. doi: 10.1016/j.evalprogplan.2015.03.005.

[53] Staley, K. (2009) Exploring Impact: Public Involvement in NHS, Public Health and Social Care Research. Eastleigh.

[54] Stilgoe, J., Owen, R. and Macnaghten, P. (2013) 'Developing a Framework for Responsible Innovation', Research Policy, 42(9), 1568-1580. doi: 10.1016/j.respol.2013.05.008

[55] Tippins, P., Bell, M. and Lerner, S. (1998) Building Relationships Between University and Community Paths to Partnership. Boulder and Littlefield: Rowman and University and Community as Learners in Interprofessional Education.

[56] Trench, B. (2008) 'Towards an Analytical Framework of Science Communication Models', in: 'Communicating Science in Social Contexts: New Models, New Practices'. ed. by Cheng, D. Dordrecht Springer, 119-135.

[57] Trencher, G. et al. (2017) 'Implementing Sustainability Co-Creation between Universities and Society: A Typology-Based Understanding', Sustainability, 9(4), 594. doi: 10.3390/su9040594

[58] van Hove, L. and Wickson, F. (2017) 'Responsible Research Is Not Good Science: Divergences Inhibiting the Enactment of RRI in Nanosafety', NanoEthics, 11(3), 213-228. doi: 10.1007/s11569017-0306-5

[59] Wallerstein, N. et al. (eds.) (2005) Developing and Maintaining Partnerships With Communities. San Francisco: John Wiley (Methods in communitybased participatory research for health).

[60] Wang, K.H. et al. (2017) 'Using Community-based Participatory Research and Organizational Diagnosis to Characterize Relationships Between Community Leaders and Academic Researchers', Preventive Medicine Reports, 7, 180-186. doi: 10.1016/j.pmedr.2017.06.007
[61] Weerts, D.J. and Sandmann, L.R. (2010) 'Community Engagement and Boundary-Spanning Roles at Research Universities', The Journal of Higher Education, 81(6), 632-657. doi: $10.1080 / 00221546.2010 .11779075$

[62] Winterbauer, N.L. and Myers, C. (2013) 'Pracademics as Culture Brokers in Practice-based Participatory Research'. Proceedings of the Keeneland Conference, 'Public Health Services \& Systems Research'. Held April 2018. Lexington, KY.

[63] Winterbauer, N.L. et al. (2016) 'Applying Community-Based Participatory Research Partnership Principles to Public Health PracticeBased Research Networks', SAGE Open, 6(4), 215824401667921. doi: $10.1177 / 2158244016679211$ 